Захарчук В.І., Захарчук О.В., Тарасюта Ю.С., Кулик В.В. Луцький національний технічний університет

\title{
ДОСЛІДЖЕННЯ ПОКАЗНИКІВ ВАНТАЖНОГО АВТОМОБІЛЯ 3 ПЕРЕОБЛАДНАНИМ 3 ДИЗЕЛЯ ГАЗОВИМ ДВИГУНОМ
}

\footnotetext{
В статті наведено результати розрахункових досліджень впливу експлуатаційних факторів на витрату палива та токсичність відпрацьованих газів вантажного автомобіля 3 переобладнаним 3 дизеля газовим двигуном. Встановлено, що більш екологічно небезпечним на 31,5...39,5 \% є транспортний засіб з дизелем при збільшенні витрати палива автомобілем з газовим двигуном на 18,1...22,6 \%. Також встановлено, що 3 підвищенням маси вантажу та при збільшені коефіцієнта опору кочення суттєво підвищується витрата палива та погіршуються екологічні показники вантажного автомобіля з переобладнаним з дизеля газовим двигуном. викиди.

Ключові слова: газовий двигун, експлуатаційні фактори, їздовий цикл, витрата палива, шкідливі
}

Постановка проблеми. Інтенсивне збільшення ціни на традиційні палива за останні роки та забруднення навколишнього середовища викидами шкідливих речовин (ШР) 3 відпрацьованими газами (ВГ) різних видів техніки визначили актуальність досліджень використання альтернативних палив. Одним 3 дійових шляхів зменшення витрат на дизельне паливо (ДП) та зниження викидів ШР з ВГ дизелів $\epsilon$ використання стиснутого природного газу (СПГ).

Аналіз останніх досліджень. Як показали попередні наукові дослідження $[1,2,3]$, одним 3 найкращих способів поліпшення екологічних показників транспортних засобів (ТЗ) та економії витрат на ДП $є$ їх конвертація для роботи на СПГ. Конвертуванням дизелів у газові двигуни займаються в США, Німеччині, Італії, Франції, Японії, Україні та інших країнах світу $[3,4,5,6,7]$.

Порівняльні дослідження, виконані при роботі автотракторних дизелів на ДП та СПГ, свідчать про зміну паливної економічності та токсичності ВГ двигуна при переході з одного палива на інший [8]. Також відрізняється закономірність зростання витрати палива та викидів ШР 3 ВГ при підвищенні навантаження на двигун (завантаження Т3), зміні коефіцієнта опору кочення, кута нахилу повздовжнього профілю дороги та ін $[3,8]$.

Таким чином, на сьогоднішній день актуальні дослідження які направлені на вивчення закономірностей зміни витрати палива та викидів ШР з ВГ газового двигуна вантажного автомобіля при роботі на СПГ в залежності від експлуатаційних факторів.

Формування цілей роботи. Метою роботи є визначення витрати палива та викидів ШР з ВГ при русі вантажного автомобіля 3 переобладнаним 3 дизеля газовим двигуном в залежності від експлуатаційних факторів.

Основна частина. Об’єктом дослідження є вантажний автомобіль ГАЗ 3309 з переобладнаним 3 дизеля газовим двигуном. Дослідження впливу експлуатаційних факторів на витрату палива та викиди ШР з ВГ газовим двигуном ТЗ виконано шляхом математичного моделювання. Зміну режимів роботи газового двигуна та відповідну зміну режимів руху вантажного автомобіля, що задано їздовим циклом, описано рядом алгебраїчних та диференціальних рівнянь [8].

Щоб результати порівняльного аналізу в характерних умовах руху автомобіля максимально повно відповідали реальним умовам експлуатації, розгін запропоновано здійснювати при максимальних (за весь період руху по циклу) положеннях органів управління паливоподачею, обох типів двигунів. Розгін ТЗ імітувався з першої по п’яту передачі транспортного ряду. Усталений рух моделювався зі сталою швидкістю на п'ятій передачі. Режим сповільнення - рух автомобіля накатом, при якому двигун працює в режимі холостого ходу.

В табл. 1 наведено показники ТЗ з дизелем і газовим двигуном (маса вантажу $m_{\mathrm{B}}=4000$ кг, довжина циклу $S=1000$ м, коефіцієнт опору кочення $\left.f_{0}=0,016\right)$, які отримано шляхом розрахунку на математичній моделі.

На рис. 1 зображено відтворений на математичній моделі рух вантажного автомобіля 3 різними двигунами за прийнятим їздовим циклом. 
(C) Захарчук В.І., Захарчук О.В., Тарасюта Ю.С., Кулик В.В. 2019

Таблиця 1 - Показники вантажного автомобіля з дизелем та газовим двигуном в прийнятому їздовому циклі

\begin{tabular}{|l|c|c|c|c|}
\hline \multirow{2}{*}{ Тип двигуна } & \multicolumn{4}{|c|}{ Показники вантажного автомобіля } \\
\cline { 1 - 5 } & Час розгону, с & $\begin{array}{c}\text { Час } \\
\text { виконання } \\
\text { циклу, с }\end{array}$ & Шлях розгону, м & $\begin{array}{c}\text { Витрата енергії } \\
\text { палива, МДж/км }\end{array}$ \\
\hline Газовий двигун & 50,5 & 139,5 & 46,3 & 11,12 \\
\hline Дизель & 54 & 143,5 & 52,6 & 9,053 \\
\hline
\end{tabular}
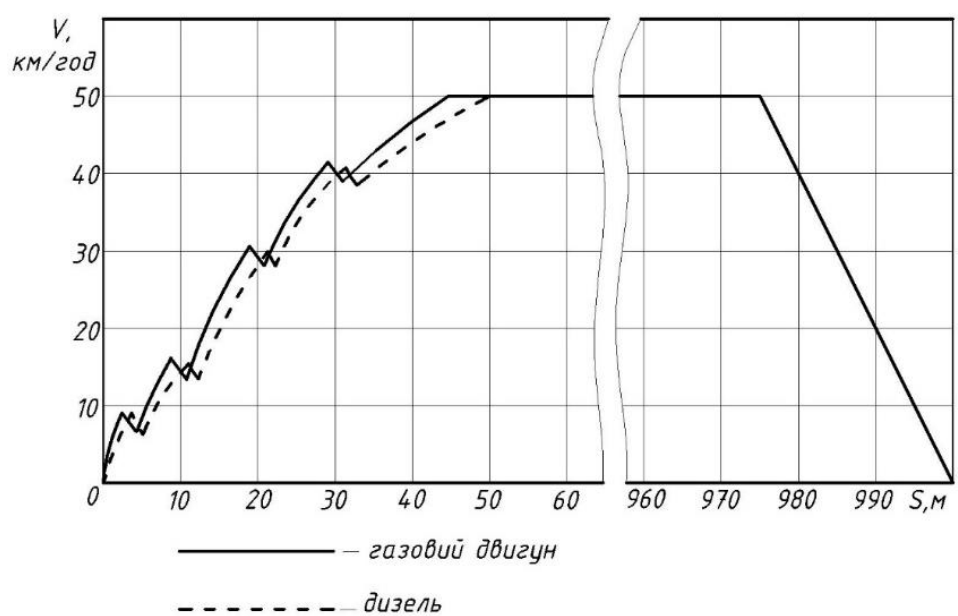

Рисунок 1 - Відтворена на математичній моделі швидкість руху вантажного автомобіля 3 різними двигунами за прийнятим їздовим циклом

На рис. 2 показано отримані шляхом розрахунку на математичній моделі в залежності від маси вантажу $m_{\mathrm{B}}$ : витрату палива $g_{n}$ в енергетичних одиницях на 1 км пробігу вантажного автомобіля 3 дизелем і газовим двигуном; питомі викиди оксиду вуглецю $g_{C O}$, вуглеводнів $g_{C H}$, оксидів азоту $g_{N O x}$, твердих часток $g_{c}$ та сумарні питомі, приведені до оксиду вуглецю $\Sigma C O$ викиди шкідливих речовин.

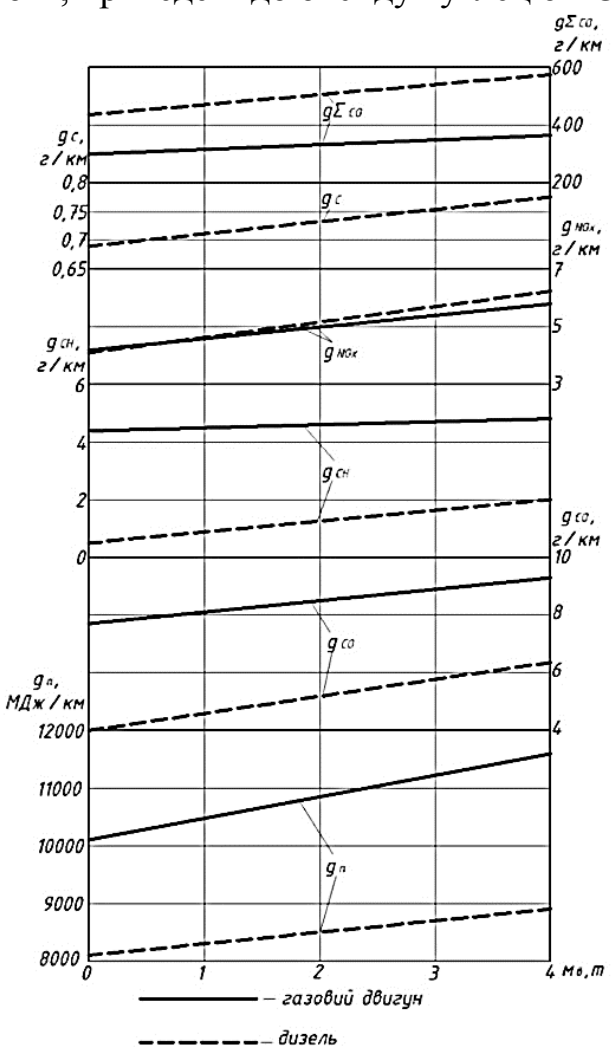

Рисунок 2 - Залежності витрати палива та викидів ШР від маси вантажу вантажного автомобіля з газовим двигуном та дизелем 
3 цих залежностей видно, що вантажний автомобіль 3 дизелем витрачає менше палива на $18,1 \ldots 22,6 \%$, викиди $C O$ у автомобіля $з$ дизелем менші відповідно на $31,5 \ldots 48,7$ \%, $C H$ відповідно менші на $56,5 \ldots 88,6$ \% ніж у автомобіля з газовим двигуном. Це пояснюється тим, що газовий двигун

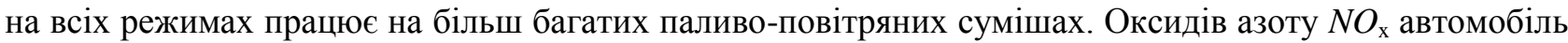
3 дизелем викидає на 8,1 \% більше. На відміну від автомобіля з газовим двигуном, автомобіль 3 дизелем викидає ще і тверді частки. Порівнюючи сумарні питомі приведені до оксиду вуглецю $\Sigma C O$, викиди шкідливих речовин, з урахуванням відносної агресивності, видно, що більш токсичним (на $31,5 \ldots 39,5 \%) є$ автомобіль з дизелем.

Дорожні умови визначаються, в основному, фізико-механічними характеристиками дорожнього покриття та грунту. До них належать: структура і механічний склад, вологість, пористість, опір зсувним і стискальним навантаженням. Значний вплив на формування дорожніх умов має і рельєф місцевості [9].

На витрату палива та викиди ШР з ВГ двигуна при прямолінійному русі транспортного засобу в значній мірі впливає коефіцієнт опору кочення коліс $f_{0}$.

Враховуючи велику кількість факторів, які впливають на величину $f_{0}$, для розрахунків користуються його середнім значенням. Так $f_{0}$ асфальтобетонної або цементобетонної дороги складає $0,014 \ldots 0,020, f_{0}$ дороги 3 гравійним покриттям $0,020 \ldots 0,025, f_{0}$ дороги 3 кам'яної бруківки складає $0,023 \ldots 0,030, f_{0}$ грунтової сухої дороги $0,025 \ldots 0,035, f_{0}$ грунтової мокрої дороги $0,050 \ldots 0,15$ [9].

Порівняння показників вантажного автомобіля при різних коефіцієнтах опору кочення $f_{0}$ здійснювалось за наступною методикою. Спочатку за допомогою математичних моделей визначали показники розгону. При розрахунках розгін здійснювався до кінцевої швидкості, а потім рух відбувався зі сталою швидкістю до кінця циклу. 3 врахуванням розгону і руху зі сталою швидкістю визначались загальні показники витрати палива та викиди шкідливих речовин при однаковій відстані циклу.

На рис. 3 наведені залежності витрати палива $\mathrm{g}_{\text {п }}$ викидів ШР з ВГ двигуна: $\mathrm{g}_{\mathrm{CO}}, \mathrm{g}_{\mathrm{CH}}, \mathrm{g}_{\mathrm{NOx}}$, час виконання циклу та сумарні, приведені до СО викидів ШР $g_{\Sigma с о}$, вантажного автомобіля 3 газовим двигуном, з завантаженням 4000 кг, при різних швидкостях руху на прямій передачі від коефіцієнта опору кочення дороги $f_{0}$.

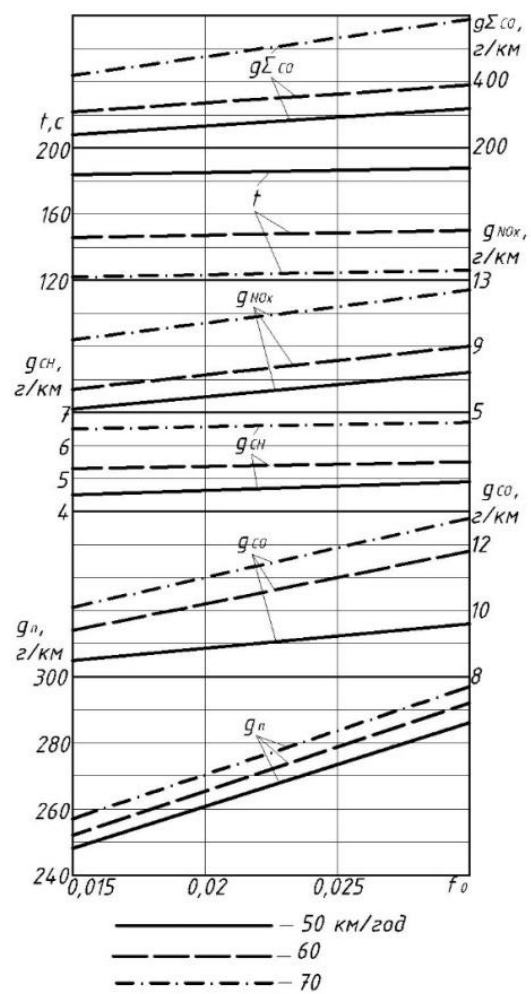

Рисунок 3 - Вплив коефіцієнта опору кочення на показники вантажного автомобіля з газовим двигуном при різній швидкості усталеного руху на прямій передачі

При порівнянні приведених показників за цикл видно, що зменшення швидкості руху на прямій передачі 370 до 50 км/год призводить до збільшення часу проходження циклу вантажним автомобілем на 34 \%. При цьому витрата палива $\mathrm{g}_{\text {п }}$ та викиди ШР $\mathrm{g}_{\mathrm{CO}}, \mathrm{g}_{\mathrm{CH}}, \mathrm{g}_{\mathrm{NOx}}$ зменшуються. 
Збільшення $f_{0}$ з 0,016 до 0,03 призводить до збільшення витрати палива на 14 \%, збільшення викидів ШР газовим двигуном: $\mathrm{g}_{\mathrm{CO}}$ на $11 \ldots 22 \%$, $\mathrm{g}_{\mathrm{CH}}$ на $2 \ldots 7 \%$, $\mathrm{g}_{\mathrm{NOx}}$ на $24 \ldots 25 \%$. Сумарні, приведені до СО викиди ШР $g_{\Sigma с о}$, збільшуються на $26 \ldots 29 \%$.

Зростання швидкості в циклі на прямій передачі з 50 до 70 км/год збільшує витрату палива на 5 $\%$, також збільшує викиди ШР газовим двигуном: g $\%$. Сумарні, приведені до СО викиди ШР $g_{\Sigma с о}$, збільшуються на $44 \ldots 45 \%$.

3 приведених порівняльних показників за цикл видно, що рух вантажного автомобіля із швидкістю 50 км/год на прямій передачі, при різних коефіцієнтах опору руху $f_{0}$ найбільш доцільний. При такій швидкості руху спостерігаються найкращі економічні та екологічні показники, хоча час проходження циклу збільшується.

На рис. 4 наведені залежності витрати палива $\mathrm{g}_{\text {п }}$ викидів ШР 3 відпрацьованими газами двигуна: $\mathrm{g}_{\mathrm{CO}}, \mathrm{g}_{\mathrm{CH}}, \mathrm{g}_{\mathrm{NOx}}$, час виконання циклу та сумарні, приведені до СО викиди ШР $g_{\Sigma C O}$, вантажного автомобіля 3 газовим двигуном від коефіцієнта опору кочення $f_{0} 3$ різними завантаженнями (2 т та 4 т).

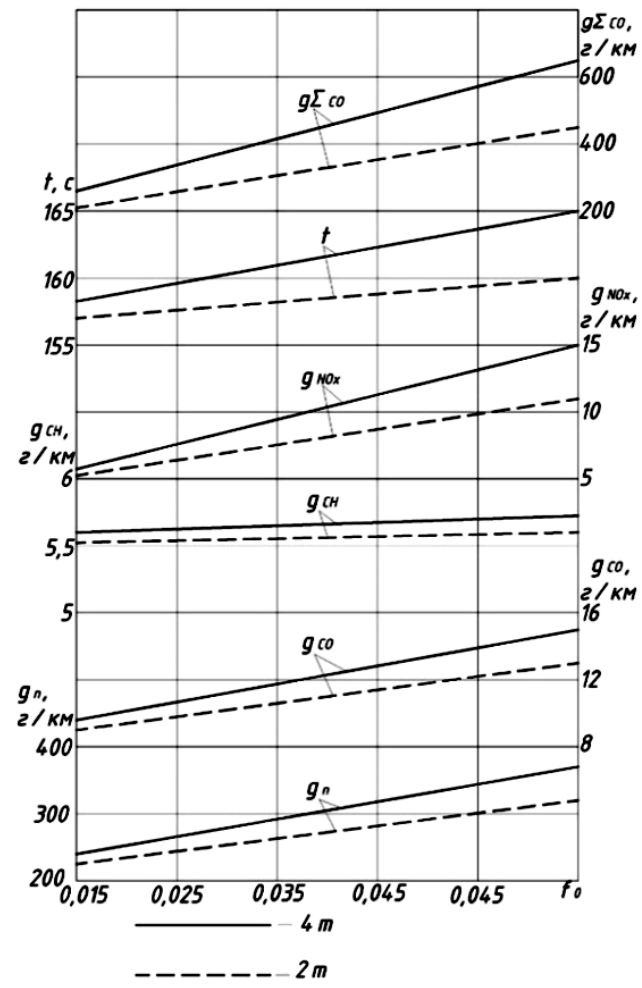

Рисунок 4 - Вплив коефіцієнта опору кочення на показники вантажного автомобіля з газовим двигуном $з$ різним завантаженням

При порівнянні приведених показників за цикл видно, що збільшення коефіцієнта опору кочення $f_{0}$ призводить до збільшення часу проходження Т3 циклу. При цьому витрата палива $\mathrm{g}_{\text {п }}$ та викиди ШР $\mathrm{g}_{\mathrm{CO}}, \mathrm{g}_{\mathrm{CH}}, \mathrm{g}_{\mathrm{NOx}}$ також збільшуються.

Збільшення $f_{0} 30,016$ до 0,065 з різними завантаженнями приводить до збільшення витрати палива на $5 \ldots 15 \%$, викидів $\mathrm{g}_{\mathrm{CO}}$ на $7 \ldots 15 \%$, викидів $\mathrm{g}_{\mathrm{CH}}$ на $2 \ldots 7 \%$, викидів $\mathrm{g}_{\mathrm{NOx}}$ на $14 \ldots 26 \%$, сумарних, приведених до СО викидів ШР $g_{\Sigma С O}$ на $13 \ldots .25 \%$ та часу виконання циклу t на $1 \ldots .5 \%$.

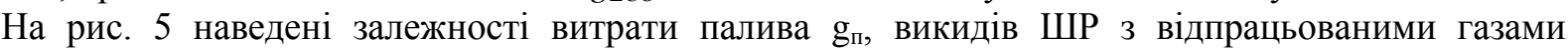
двигуна: $\mathrm{g}_{\mathrm{CO}}, \mathrm{g}_{\mathrm{CH}}, \mathrm{g}_{\mathrm{NOx}}$, часу виконання циклу та сумарних, приведених до СО викидів ШР $g_{\Sigma C O}$, вантажного автомобіля з газовим двигуном при різних швидкостях руху на прямій передачі з різними завантаженнями.

При проведення аналізу отриманих показників за цикл видно, що зменшення швидкості руху на прямій передачі з 70 до 50 км/год призводить до збільшення часу проходження циклу вантажного автомобіля на 31,5 \%. При цьому витрата палива $\mathrm{g}_{\text {п }}$ та викиди ШР $\mathrm{g}_{\mathrm{CO}}, \mathrm{g}_{\mathrm{CH}}, \mathrm{g}_{\mathrm{NOx}}$ зменшуються.

Збільшення завантаження при швидкості руху 50 км/год 30 до 4 т призводить до збільшення витрати палива $\mathrm{g}_{\text {п }}$ на 18,8 \% та збільшення викидів ШР газового двигуна $\mathrm{g}_{\mathrm{co}}$ на 14,8 \%, $\mathrm{g}_{\mathrm{cH}}$ на 4,6 \% та $\mathrm{g}_{\mathrm{NOx}}$ на 18,2 \%. Сумарні, приведені до СО викидів ШР $g_{\Sigma с о}$ збільшуються на 20,4 \%. 


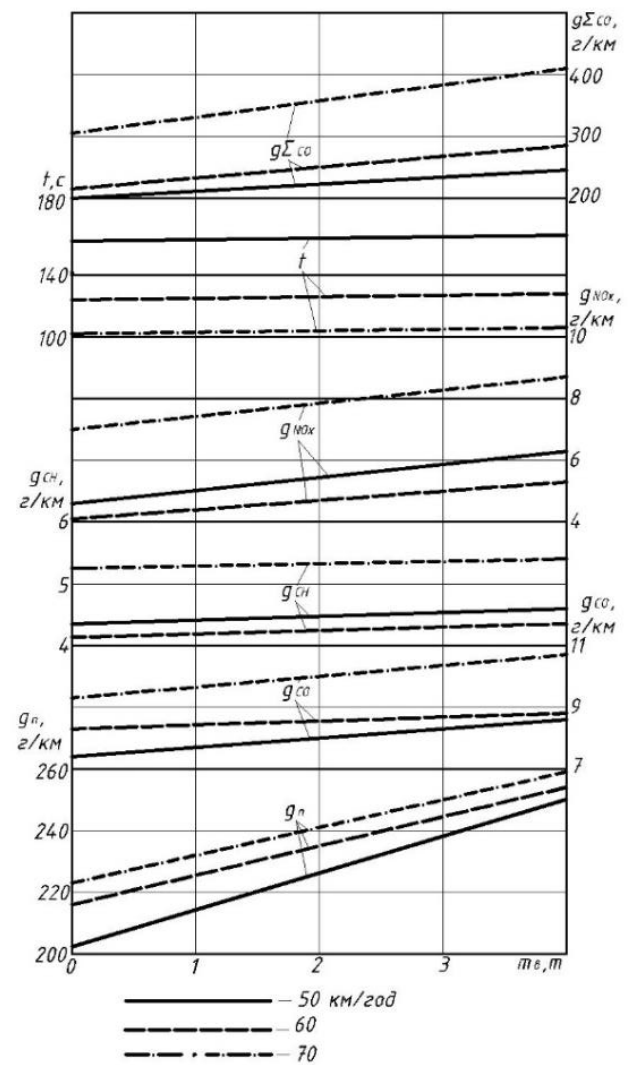

Рисунок 5 - Вплив завантаження на показники вантажного автомобіля 3 газовим двигуном 3 різними швидкостями усталеного руху на прямій передачі

Висновки. 3 проведених порівняльних теоретичних досліджень можна побачити, що більш екологічно небезпечним на $31,5 \ldots 39,5 \% €$ ТЗ з дизелем при збільшенні витрати палива автомобілем 3 газовим двигуном на 18,1..22,6 \%. Також встановлено, що з підвищенням маси вантажу та при зміні коефіцієнта опору кочення суттєво підвищується витрата палива та погіршуються екологічні показники вантажного автомобіля з переобладнаним з дизеля газовим двигуном. Наступним етапом роботи будуть теоретичні дослідження впливу параметрів керування газовим двигуном вантажного автомобіля для покращення його паливної економічності.

1. Льотко В. Применение альтернативных топлив в ДВС / В. Льотко, В. Н. Луканин, А. С. Хачиян. - М.: МАДИ (ТУ), 2000. $-331 \mathrm{c}$.

2. Гайворонский А. И. Использование природного газа и других альтернативных топлив в дизельных двигателях / А. И. Гайворонский, В. А. Марков, Ю. В. Илатовский. - М.: ООО «ИРЦ Газпром», 2007. - 480 с.

3. Матейчик В. П. Методи оцінювання та способи підвищення екологічної безпеки дорожніх транспортних засобів: монографія / В. П. Матейчик. - К.: НТУ, 2006. - 216 с.

4. Hamling P. "Down Under" success with natural gas buses / P. Hamling // NGV Worldwide. - 2002. - P. 11.

5. Nylund N. Pathways For Natural Gas Into Advanced Vehicles / N. Nylund, J. Laurikko, M. Ikonen. - Brussel: IANGV. 2002. -105 p.

6. Mori K. Worldwide Trends in Heavy-Duty Diesel Engine Exhaust Legislation and Compliance Technologies / K. Mori. Warrendale, USA: SAE international, 2001. - 46 p.

7. Газовые двигатели // Журнал «Автомайстерня». - 2006. - № 12. - С. 30-32.

8. Гутаревич Ю. Ф. Снижение вредных выбросов автомобиля в эксплуатационных условиях /

Ю.Ф. Гутаревич. - К.: Вища школа, 1991. - 179 с.

9. Бортницкий П. И. Тягово-скоростные качества автомобилей / П. И. Бортницкий, В. И. Задорожный. - К.: Вища школа, 1978. - $176 \mathrm{c}$.

\section{REFERENCES}

1. L'otko V., Lukanin V. N. \& Khachyyan A. S. (2000). Primenenie al'ternativnyh topliv v DVS. MADI (TU), 331.

2. Hayvoronskyy A. Y., Markov V. A. \& Ylatovskyy Y. V. (2007) Yspol'zovanye pryrodnoho haza y druhykh al'ternatyvnukh toplyv v dyzel'nukh dvyhatelyakh. OOO "YRTs Hazprom", 480.

3. Mateychyk V. P. (2006). Metody otsinyuvannya ta sposoby pidvyshchennya ekolohichnoyi bezpeky dorozhnikh transportnykh zasobiv: monohrafiya. NTU, 216.

4. Hamling P. (2002) "Down Under" success with natural gas buses. NGV Worldwide, 11.

5. Nylund N., Laurikko J. \& Ikonen M. (2002). Pathways For Natural Gas Into Advanced Vehicles. IANGV, 105.

6. Mori K. (2001). Worldwide Trends in Heavy-Duty Diesel Engine Exhaust Legislation and Compliance Technologies. SAE international, 46 . 
7. Gazovye dvigateli. (2006). Zhurnal "Avtomajsternja",30-32.

8. Gutarevich Y. F. (1991). Snigenie vrednyh vybrosov avtomobil'ia v ekspluatacionnyh uslovi'ah. Vyshcha shkcola, 1991.

9. Bortnickij P. I. (1978). Tjagovo-skorostnye kachestva avtomobilej. Vyshcha shkcola,176.

Захарчук В.И., Захарчук О.В., Тарасюта Ю.С., Кулык В.В. Исследование показателей грузового автомобиля с переоборудованным из дизеля газовым двигателем

В статье приведены результаты расчетных исследований влияния эксплуатационных факторов на расход топлива и токсичность отработавших газов грузового автомобиля с переоборудованным с дизеля газовым двигателем. Установлено, что более экологически опасным на $31,5 \ldots 39,5 \%$ является транспортное средство с дизелем при увеличении расхода топлива автомобилем с газовым двигателем на $18,1 \ldots 22,6 \%$. Также установлено, что с повышением массы груза и при увеличении коэффициента сопротивления качению существенно повышается расход топлива и ухудшаются экологические показатели грузового автомобиля с переоборудованным с дизеля газовым двигателем.

Ключевые слова: газовый двигатель, эксплуатационные факторы, ездовой цикл, расход топлива, вредные выбросы.

V. Zaharchuk, O. Zaharchuk, Y. Tarasiuta, V. Kulyk. Research of indexes of the cargo automobile with the gas engine reconstruction from a diesel.

The article presents the results of the calculations of the influence of operational factors on the fuel consumption and the toxicity of the exhaust gases of a truck with a diesel engine retrofitted with a gas engine. The research is done through the mathematical modeling. For comparative researches the motion of a gas engine and diesel engine with a ride cycle was restored, and the dependencies of fuel consumption and emissions of harmful substances on the weight of the load are shown. It has been established that more environmentally dangerous at $31.5 \ldots 39.5 \%$ is a diesel vehicle with an increase in fuel consumption by a car with a gas engine of $18.1 \ldots 22.6 \%$. The analysis of the influence of the coefficient of rolling resistance on the parameters of a truck with a gas engine from the speed of steady motion on a direct transmission and on loading is carried out. Also, the research of the impact of loading on the indicators of a car with a gas engine from the rate of steady motion on a direct transmission has been conducted. It is established that with the increase in the weight of the load and the increase in the rolling resistance coefficient of the wheels significantly increased fuel consumption and deteriorates the environmental performance of a truck with a diesel engine replaced by a gas engine.

Key words: gas engine, operating factors, ride cycle, fuel consumption, harmful emissions.

ЗАХАРЧУК Віктор Іванович, доктор технічних наук, професор кафедри автомобілів i транспортних технологій, Луцький національний технічний університет e-mail: victavto@gmail.com.

ЗАХАРЧУК Олег Вікторович, кандидат технічних наук, доцент кафедри автомобілів i транспортних технологій, Луцький національний технічний університет e-mail: Zaharchukov205@gmail.com.

ТАРАСЮТА Юрій Сергійович, магістр кафедри автомобілів і транспортних технологій, Луцький національний технічний університет.

КУЛИК Владислав Володимирович, магістр кафедри автомобілів і транспортних технологій, Луцький національний технічний університет.

ЗАХАРЧУК Виктор Иванович, доктор технических наук, профессор кафедры автомобилей и транспортных технологий, Луцкий национальный технический университет e-mail: victavto@gmail.com.

ЗАХАРЧУК Олег Викторович, кандидат технических наук, доцент кафедры автомобилей и транспортных технологий, Луцкий национальный технический университет e-mail: Zaharchukov205@gmail.com.

ТАРАСЮТА Юрий Сергеевич, магистр кафедры автомобилей и транспортных технологий, Луцкий национальный технический университет.

КУЛЫК Владислав Владимирович, магистр кафедры автомобилей и транспортных технологий, Луцкий национальный технический университет.

Victor ZAHARCHUK, Doctor of Technical Sciences, Professor of the department of motor cars and transport technologies, Lutsk National Technical University e-mail: victavto@gmail.com.

Oleg ZAHARCHUK, $\mathrm{PhD}$, associate professor of the department of motor cars and transport technologies, Lutsk National Technical University e-mail:Zaharchukov205@gmail.com.

Yuriy TARASIUTA, Master of the department of motor cars and transport technologies, Lutsk National Technical University

Vladislav KULYK, Master of the department of motor cars and transport technologies, Lutsk National Technical University 